Part B: Applied Biomaterials

\title{
Root canal hydrophobization by dentinal silanization: improvement of silicon-based endodontic treatment tightness.
}

\begin{tabular}{|c|c|}
\hline Journal: & Journal of Biomedical Materials Research: Part B - Applied Biomaterials \\
\hline Manuscript ID: & JBMR-B-12-0276.R1 \\
\hline Wiley - Manuscript type: & Original Research Report \\
\hline Date Submitted by the Author: & 04-Aug-2012 \\
\hline Complete List of Authors: & $\begin{array}{l}\text { Collart Dutilleul, Pierre-Yves; Laboratoire Biosanté et Nanoscience EA 4203, } \\
\text { Université Montpellier1 } \\
\text { Gaitan Fonseca, Cesar; Universidad Autónoma de San Luis Potosi, } \\
\text { Doctorado Institucional en Ingeniería y Ciencia de Materiales } \\
\text { Zimányi, Lászlo; Biological Research Centre of the Hungarian Academy of } \\
\text { Sciences, Institute of Biophysics } \\
\text { Romieu, Olivier; Laboratoire Biosanté et Nanoscience EA 4203, Université } \\
\text { Montpellier1 } \\
\text { Pozos-Guillen, Amaury; Universidad Autónoma de San Luis Potosi, } \\
\text { Doctorado Institucional en Ingeniería y Ciencia de Materiales } \\
\text { Semetey, Vincent; Institut Curie, Centre de Recherche, UMR } 168 \text { CNRS, } \\
\text { Institut Curie } \\
\text { Cuisinier, Frédéric; University of Montpellier, UFR Odontologie } \\
\text { Pérez, Elías; Doctorado Institucional en Ingeniería y Ciencia de Materiales, } \\
\text { Universidad Autónoma de San Luis Potosi } \\
\text { Levallois, Bernard; Laboratoire Biosanté et Nanoscience EA 4203, } \\
\text { Université Montpellier1 }\end{array}$ \\
\hline Keywords: & $\begin{array}{l}\text { dental/craniofacial material, endodontics, FTIR, hydrophobic, surface } \\
\text { modification }\end{array}$ \\
\hline
\end{tabular}

\section{SCHOLARONEm}

Manuscripts 
Root canal hydrophobization by dentinal silanization: improvement of silicon-based endodontic treatment tightness.

Pierre-Yves Collart Dutilleul ${ }^{\mathrm{a}}$, Cesar Gaitan Fonseca ${ }^{\mathrm{b}}$, László Zimányi ${ }^{\mathrm{ad}}$, Olivier Romieu ${ }^{\mathrm{a}}$, Amaury J. Pozos-Guillen ${ }^{\mathrm{b}}$, Vincent Semetey ${ }^{\mathrm{c}}$, Frédéric Cuisinier ${ }^{\mathrm{a}}$, Elías Pérez ${ }^{\mathrm{b}}$, Bernard Levallois ${ }^{\mathrm{a}}$.

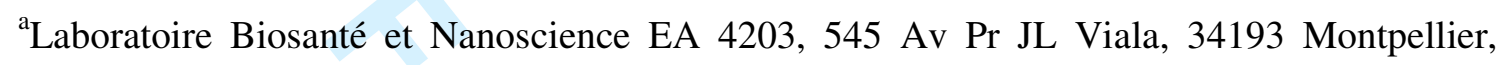
France

${ }^{\mathrm{b}}$ Doctorado Institucional en Ingeniería y Ciencia de Materiales, Universidad Autónoma de San Luis Potosí, Alvaro Obregón 64, 78000 SLP, Mexico

${ }^{\mathrm{c}}$ Institut Curie, Centre de Recherche, UMR 168 CNRS, 75248 Paris, France

${ }^{\mathrm{d}}$ Institute of Biophysics, Biological Research Centre of the Hungarian Academy of Sciences, Temesvárikrt. 62, P.O. Box 521, H-6701 Szeged, Hungary

Corresponding author: Frédéric Cuisinier

EA4203, 545 avenue Viala, 34193, Montpellier France.

Tel: 33411759225 fax: +33411759201

frederic.cuisinier@univ-montp1.fr

John Wiley \& Sons, Inc. 


\begin{abstract}
A new strategy to improve silicon-based endodontic treatment tightness by dentine hydrophobization is presented in this work. This strategy uses silanization of the root dentine to obtain a hydrophobic surface to reduce the number and size of pores between sealer and dentine and to increase water repellence. We developed a dentine pretreatment protocol of applying EDTA followed by sodium hypochlorite, and then another application of EDTA. The resulting exposure of collagen fibers significantly improves the efficiency of silanization, thus increasing the hydrophobicity of silanized pretreated dentine compared to silanized raw dentine. Four silanization protocols using octadecyltrichlorosilane (OTS) or octadecyltriethoxysilane (OTES) and 4 solvents, ethyl acetate, acetone, ethanol and dichloromethane, were evaluated using contact angle measurements and Fourier transform infrared spectroscopy (FTIR). Protocols using OTS were more efficient to turn dentine into a hydrophobic surface, by aliphatic carbon chain graft. We selected OTS silanization using ethyl acetate as a solvent because of ethyl acetate's superior biocompatibility. Effects of this silanization protocol on the tightness of a silicone-based sealer (Roekoseal ${ }^{\circledR}$ ) were evaluated by gas permeability tests and water permeability tests. Water and gas permeability tests both demonstrate significant improvement in endodontic sealing after the dentine hydrophobic treatment.
\end{abstract}




\section{INTRODUCTION}

Endodontic treatment relies on hermetically sealing the root canal. Unfortunately, regardless of endodontic technique or the materials used, a perfect seal is impossible to achieve. ${ }^{1,2}$ Although contemporary research identifies the two most critical factors in preventing and treating endodontic diseases as cleaning and shaping of the root canal, root filling tightness may play an important role in securing short- and long-term periapical health. ${ }^{3,4}$ A hermetic seal prevents bacterial infection or re-infection of the periapical zone by isolating the treated canal. ${ }^{5}$ If the root canal filling fails to provide a complete seal, seepage of fluids can provide a substrate for bacterial growth. ${ }^{6}$

We recently demonstrated that fluid penetration at the dentine-sealer interface depends on the hydrophobicity of the surfaces involved. ${ }^{7}$ Hydrophobicity reduces liquid penetration by reversing capillary pressure..$^{8}$ A hydrophobic surface treatment of dentinal walls could prevent or limit fluid penetration by reversing capillary pressure and reducing the gap between the dentinal wall and root canal sealer by means of hydrophobic bonds. We have considered existing techniques of hydrophobization used in several fields: the textile industry, masonry, the drug delivery industry and the food industry to render root canal walls hydrophobic. ${ }^{9,10,11,12}$ Finally we choose to use carboxy-terminal domains of collagen exposing hydroxyl groups usable for silanization. ${ }^{13,14}$ For silanization we used either octadecyltrichlorosilane (OTS), which has been previously investigated for the chemical hydrophobization of silica surfaces, or octadecyltriethoxysilane (OTES). ${ }^{15,16}$ Silanization was first performed with OTS (octadecyltrichlorosilane) in DCM (dichloromethane); then silanization was repeated with other, more biocompatible solvents, such as ethanol for OTES and ethyl acetate or acetone for OTS. The effects of different surface modifications were investigated by contact angle measurement, FTIR and scanning electron microscopy (SEM). 
Our aims were to modify dentine surface tension using biocompatible chemicals and to select the most efficient silanization protocol. We investigated the relationship between the dentine hydrophobization processes and tightness of silicon-based endodontic treatments.

\section{MATERIALS AND METHODS}

\section{Chemical products}

Solvents and silanes used were obtained from Sigma-Aldrich (Munich, Germany): octadecyltrichlorosilane $\quad\left(\mathrm{CH}_{3}\left(\mathrm{CH}_{2}\right)_{17} \mathrm{SiCl}_{3} \geq 90 \%\right), \quad$ octadecyltriethoxysilane $\quad$ (OTES) $\left(\mathrm{CH}_{3}\left(\mathrm{CH}_{2}\right)_{17} \mathrm{Si}\left(\mathrm{OCH}_{2} \mathrm{CH}_{3}\right)_{3} 90 \%\right)$, dichloromethane (DCM) $(\mathrm{CH} 2 \mathrm{Cl} 2$, anhydrous $\geq 99.8 \%)$, ethyl acetate (CH3CO2CH3, anhydrous 99.8\%), acetone $(\mathrm{CH} 3 \mathrm{COCH} 3, \geq 99.8 \%$, Chromasolv $^{\circledR}$ ), ethanol (anhydrous $\geq 99.5 \%$ ) and acetic acid (ReagentPlus ${ }^{\circledR}, \geq 99 \%$ ). Ethylene diamine tetra acetic acid disodium salt hydrate (EDTA) and sodium thiosulfate $\left(\mathrm{Na}_{2} \mathrm{~S}_{2} \mathrm{O}_{3}\right.$, pentahydrate, 99\%) were obtained from Acros Organics (Geel, Belgium). Sodium hydroxide $(\mathrm{NaOH}, 10 \mathrm{~mol} / \mathrm{L})$ and potassium iodide (KI, AnalR Normapur) were obtained from VWR (Radnor, Pennsylvania, USA). Sodium hypochlorite (NaOCl, 6-14\%) was obtained from Merck (Darmstadt, Germany) and hydrochloric acid (HCl, 37\%, 10N) from Sigma-Aldrich. Sodium azide $\left(\mathrm{NaN}_{3}\right)$ was obtained from Sigma-Aldrich.

\section{Specimen preparation for chemical pretreatment and silanization}

All teeth used in this work were extracted for clinical reasons and collected according to French ethical regulations. All patients were above 18 years of age. Informed consent was obtained from all patients. Caries-free freshly extracted human teeth stored immediately after extraction for a maximum of 1 month in $0.1 \%$ sodium azide solution were used in this study. We used 30 anterior teeth to assess endodontic tightness with gas and water permeability techniques: the coronal part of each tooth was removed with a diamond bur under water

John Wiley ${ }^{2}$ Sons, Inc. 
coolant, retaining a $15 \mathrm{~mm}$ long root. We used 30 extracted molars or premolars to assess pretreatment and silanization efficiency: teeth were cleaned of soft tissue debris and then cut longitudinally in $1 \mathrm{~mm}$ thick slices using an Isomet 2000 saw (Buehler, Lake Bluff, USA). Smooth dentine surfaces were obtained by wet-grinding for 1 minute with SiC paper of abrasiveness 1200 with an ESC200GT polishing machine (ESCIL, Lyon, France). The specimens were randomly assigned to groups of 5 specimens for each surface modification method and each analysis method.

\section{Pretreatment}

To remove the smear layer and expose collagen at the dentine surface specimens were chemically pretreated by successive immersions in 3 solutions: EDTA 17\% $(\mathrm{pH}=7.4)$ for 3 minutes, $\mathrm{NaOCl} 2.5 \%$ for 5 minutes and EDTA $17 \%(\mathrm{pH}=7.4)$ for 3 minutes. The specimens were rinsed in distilled water between each bath. This protocol was tested by controlling 2 groups, with and without pretreatment (5 specimens in each group). Once pretreatment protocol was validated, all silanization procedures were performed with pretreated specimens.

The same procedure was used within the root canals from anterior teeth (specimens for gas and water permeability assessment) except that the chemical products were brought into the canals in a continuous flow for 3 or $5 \mathrm{~min}$, using a $25 \mathrm{~mL}$ syringe and a $0.35 \mathrm{~mm}$ diameter needle (VMK Endoneedle, 28G, $0.35 \mathrm{~mm}$, Vedefar ${ }^{\circledR}$, Brussel, Belgium)

To prepare the EDTA solution, EDTA disodium salt hydrate powder was dissolved in sodium hydroxide and distilled water. If necessary, the $\mathrm{pH}$ was adjusted to 7.4 by adding a few drops of hydrochloric acid.

To prepare the $2.5 \% \mathrm{NaOCl}$ solution, the original sodium hypochlorite solution was assayed by iodine chemical titration. The $\mathrm{NaOCl}$ was then diluted to a $2.5 \%$ concentration. 


\section{Silanization}

Silanization of root dentine slices was carried out on pretreated specimens with octadecyltrichlorosilane (OTS) in 3 different solvents and with octadecyltriethoxysilane (OTES) in ethanol and acetic acid. The solvents used with OTS were dichloromethane, ethyl acetate and acetone. The following protocol was used for silanization with OTS: The specimen was immersed in distilled water for $1 \mathrm{~min}$; in $96 \%$ ethanol for $1 \mathrm{~min}$; in the solvent (dichloromethane or ethyl acetate or acetone) for $1 \mathrm{~min}$; in a solution containing $200 \mu \mathrm{L}$ OTS in $10 \mathrm{~mL}$ of solvent for $1 \mathrm{~min}$; in the solvent for $1 \mathrm{~min}$; in $96 \%$ ethanol for $1 \mathrm{~min}$; and then stored in distilled water before contact angle or FTIR analysis. For silanization with OTES, the following protocol was used: the specimen was immersed in distilled water for $1 \mathrm{~min}$; in $96 \%$ ethanol for $1 \mathrm{~min}$; in a solution containing $10 \mathrm{~mL}$ absolute ethanol ( $\geq 99.5 \%), 200 \mu \mathrm{L}$ acetic acid and $600 \mu \mathrm{L}$ OTES for $5 \mathrm{~min}$ at $72^{\circ} \mathrm{C}$; in $96 \%$ ethanol for $1 \mathrm{~min}$; and then stored in distilled water before contact angle or FTIR analysis. The contact angle and FTIR analyses were made within 24 hours after silanization.

For the prepared root canals, silanization was carried out after endodontic preparation and chemical pretreatment with OTS in ethyl acetate. The procedure described above was followed, except that the chemical products were brought into the canals in a continuous flow for $1 \mathrm{~min}$, using a $25 \mathrm{~mL}$ plastic syringe and a $0.35 \mathrm{~mm}$ diameter needle (VMK Endoneedle, 28G, $0.35 \mathrm{~mm}$, Vedefar ${ }^{\circledR}$, Brussel, Belgium). After the last $96 \%$ ethanol rinse, the root canals were dried with sterile paper points (F3 ProTaper ${ }^{\circledR}$, Dentsply Maillefer, Ballaigues, Switzerland). Root fillings were performed immediately. All root fillings were made with a F3 ProTaper gutta-percha point and a silicone-based sealer (Roekoseal ${ }^{\circledR}$, Coltene, Altstätten, Switzerland) that has hydrophobic properties. ${ }^{17}$ After filling, the teeth were stored for 1 week at room temperature.

John Wiley ${ }^{4} \&$ Sons, Inc. 


\section{Scanning Electron Microscopy (SEM)}

Root dentine slices were observed under a FEI Quanta 200 FEG environmental scanning electron microscope (ESEM, FEI Company), with magnification from 500x up to 26000x. An accelerating voltage of $15.00 \mathrm{kV}$ was used, and a final water vapor pressure of 0.45 Torr was achieved. The specimens were placed on an adhesive tape and fixed to a 3.5 $\mathrm{cm} \times 3 \mathrm{~cm}$ copper plate. We focused on the secondary electron signal that provides topographic contrast. One advantage to using the ESEM in "wet" mode is that it is not necessary to make nonconductive specimens conductive; specimens do not need to be desiccated and coated, and thus their original characteristics may be preserved for further testing or manipulation. At each step of the pretreatment protocol we observed specimens and measured the dentinal tubules diameter ( 5 measures per specimen). Specimens were also observed after silanization.

\section{Fourier Transform Infrared Reflection-Absorption Spectroscopy (FTIR)}

Specimens were evaluated for collagen exposure and silane grafting using a Fourier transform infrared spectrometer BRUKER IFS66v (Bruker Optics, Ettlingen, Germany), to detect molecular bending, vibration, wagging and rocking of functional groups. The dentine surface analysis was conducted over a spectral range of $3500-500 \mathrm{~cm}^{-1}$ in reflectance mode, at a resolution of $2 \mathrm{~cm}^{-1}$, on $100 \times 100 \mu \mathrm{m}$ areas. The spectra obtained from FTIR were analyzed with MATLAB software (MathWorks ${ }^{\circledR}$, Natick, USA). We used hierarchical clustering analysis to examine similarities and dissimilarities among the spectra. Hierarchical clustering analysis is a way to investigate grouping in data simultaneously over multiple distance scales by creating a cluster tree, which is a multi-level hierarchy where clusters at one level are joined to clusters at the next higher level. ${ }^{18}$

John Wiley ${ }^{5}$ Sons, Inc. 
To evaluate pretreatment procedure we took 100 scans for each specimen in 3 different areas of the root (coronal, middle and apical), at the different steps of pretreatment procedure. We selected 4 clusters based on the spectral range of $1700-1200 \mathrm{~cm}^{-1}$, representing typical dentine structure for the pretreatment procedure. For silanization, we focused on the middle part of the root. We took 100 scans for each specimen and we selected 4 clusters based on the spectral range of $3000-2700 \mathrm{~cm}^{-1}$. We then plotted the means of each cluster (Fig 3).

\section{Contact angle measurement}

Water was used as the reference liquid. A sessile drop of the reference liquid was applied with a syringe onto a specimen, which was put on a plate capable of moving in three dimensions. Specimens were gently dried before measurement with an absorbent paper wipe (Kimberly Clark, Irving, USA). The profile of the water drops was recorded with a CCD camera connected to a video-acquisition card. Contact angles were measured and recorded with Visiodrop ${ }^{\circledR}$ software. Two consecutive drops $(3 \mu \mathrm{L}$ of distilled water were applied to each specimens. All specimens were evaluated for water affinity with water contact angle measurement before and after pretreatment and before and after silanization. There were 5 specimens in each group. A Student's t-test was used to compare groups with statistical significance set at $\mathrm{p}<0.05$.

\section{Gas permeability}

The teeth used for endodontic tightness assessment were also prepared by the same experienced endodontist to minimize variability. The coronal part of each tooth was removed with a diamond bur under water coolant, retaining a $15 \mathrm{~mm}$ long root. A \#08 K-File colorinox (Dentsply Maillefer, Ballaigues, Switzerland) was introduced into the canal to 
verify the apical patency until the tip was just visible at the major apical foramen. The working length was determined by subtracting $1 \mathrm{~mm}$ from this length. All canals were prepared with K-files and the ProTaper system at $300 \mathrm{rpm}$ following a sequence of K-files \#8, \#10, \#15 and ProTaper S1, S2, F1, F2, F3. A \#8 K-File was used between each Protaper to verify the apical patency. The irrigant was a $2.5 \% \mathrm{NaOCl}$ solution delivered with a 27 gauge needle. Two $\mathrm{mL}$ of irrigant was delivered between each file size. Finally, the teeth were rinsed sequentially with EDTA $17 \%$ (3 min), $\mathrm{NaOCl} 2.5 \%$ (5 min) and EDTA $17 \%$ (3 min). The teeth were randomly assigned to 2 groups: a group receiving a silanization procedure before root filling and a group directly root filled without silanization treatment. Each group contained 10 specimens. For these experiments, the silanization procedure used OTS in ethyl acetate. All root fillings were made with a F3 ProTaper gutta-percha point and a silicone-based sealer (Roekoseal ${ }^{\circledR}$, Coltene, Altstätten, Switzerland), as stated above.

We used an experimental setup developed in our laboratory, previously described by Romieu et al. ${ }^{19}$ Briefly, the prepared teeth were partially embedded in epoxy glue avoiding occlusion of canal and apex and sealed in a glass tube. After complete setting of the glue, the glass tubes were inserted between 2 chambers containing 2 different gas pressures: atmospheric pressure (P1) and negative pressure (P2). The pressure difference (Dp) between P1 and P2 was measured with a differential pressure gauge (Testo 526, Testo, Forbach, France) with an accuracy of $0.01 \mathrm{hPa}$. The evolution of the pressure difference was then converted into gas flow. All measurements were carried out at room temperature. Nitrogen (Alphagaz1, Air Liquide, Paris, France) was chosen as the leaking gas because its molecular size is similar to that of a water molecule $(0.315 \mathrm{~nm}$ for $\mathrm{N} 2$ and $0.343 \mathrm{~nm}$ for water) and because it is used classically in porometry experiments. ${ }^{20}$ Each specimen was measured 2 times for gas permeability through the root filled canal over a period of 75 min with a 
measurement taken every minute. Gas flows were determined using a Knudsen flow regime corresponding to a rarified gas environment. ${ }^{21}$

Results were analyzed using mean values, and a Student's t-test was used to compare groups, with statistical significance set at $\mathrm{p}<0.05$.

\section{Water permeability}

Ten specimens were prepared using the same method as for the gas permeability test. The specimens were randomly assigned to 2 groups, silanized and non-silanized. Each group contained 5 specimens. The experimental apparatus consisted of a pressure jar and a hose to convey water to the apical portion of the root with a constant pressure of 3 psi, as previously described. $^{22,23}$ Briefly, prepared teeth were partially embedded in epoxy glue (araldite, Huntsman LLC, Salt Lake City, USA) avoiding occlusion of the canal and apex. They were then sealed in a glass tube and fixed on the experimental apparatus. An air bubble was placed in the capillary tube connected to the coronal end of the tooth. The bubble displacement was tracked with an optical system of infrared light to calculate the instantaneous water flow between 2 to 8 minutes after injection. Negative controls were carried out with a closed glass test tube. Results were expressed in $\mu \mathrm{L} \cdot \mathrm{min}^{-1}$. The mean of results was taken within each group. A Student's t-test was used to compare group means, with statistical significance set at $\mathrm{p}<0.05$.

\section{RESULTS}

The dentinal slices were observed by SEM after successive immersions in 3 chemicals (Fig. 1). SEM observation shows that the smear layer present on raw dentine (A, B) disappears after the first EDTA treatment $(C, D)$; dentinal tubules open after the $\mathrm{NaOCl}$ rinse $(E, F)$; and subsequently wider tubules open after the second EDTA rinse $(G, H)$. The 
mean pore size for tubules is $1.62 \pm 0.14 \mu \mathrm{m}$ after first EDTA treatment, $2.43 \pm 0.14 \mu \mathrm{m}$ after $\mathrm{NaOCl}$, and $3.09 \pm 0.52 \mu \mathrm{m}$ after second EDTA rinse. SEM observation was followed by FTIR. The $1630 \mathrm{~cm}^{-1}$ peak corresponds to the stretching vibration of $\mathrm{C}=\mathrm{O}$ bond $(\mathrm{vC}=\mathrm{O})$ from amide I; the $1580 \mathrm{~cm}^{-1}$ peak corresponds to dehydrated Amide I. The $1538 \mathrm{~cm}^{-1}$ peak corresponds to the stretching vibration of $\mathrm{C}-\mathrm{N}$ bond $(\mathrm{vC}-\mathrm{N})$ from amide II. The $1445 \mathrm{~cm}^{-1}$ and $870 \mathrm{~cm}^{-1}$ peaks correspond to $\mathrm{CO}_{3}$. The $1230 \mathrm{~cm}^{-1}$ peak corresponds to Amide III; the $1170 \mathrm{~cm}^{-1}$ peak corresponds to dehydrated Amide III. The $1025 \mathrm{~cm}^{-1}$ and $960 \mathrm{~cm}^{-1}$ peaks correspond to $\mathrm{PO}_{4}{ }^{24,25}$

The spectra from all the roots were classified into 4 clusters by hierarchical cluster analysis. A typical example of each cluster is shown in Fig. 2:

-Cluster A: Weak amide I, II, III bands and strong phosphate band $\left(1025 \mathrm{~cm}^{-1}\right)$;

-Cluster B: Weak amide I, II, III bands, medium intensity phosphate band;

-Cluster C: Amide I $\left(1630 \mathrm{~cm}^{-1}\right)$ and amide II $\left(1538 \mathrm{~cm}^{-1}\right)$ bands shifted to lower wavenumber

-Cluster D: Similar to A with strong amide I $\left(1630 \mathrm{~cm}^{-1}\right)$ and amide II $\left(1538 \mathrm{~cm}^{-1}\right)$ and phosphate band $\left(1025 \mathrm{~cm}^{-1}\right)$.

The clusters are present in different areas of the root dentine (Table 1). The spectra after the first and second EDTA treatments are always different. The first EDTA treatment dissolves the smear layer, and the second demineralizes the surface. Spectra of the coronal third and the apical third are classified in the same cluster both before and after EDTA and $\mathrm{NaOCl}$ treatment. For all root areas after the three chemical treatments, all spectra are classified in cluster D, indicating good reproducibility of the pretreatment process. Cluster repartition for the three treatments in 3 crown areas (1/3 coronal, 1/3 medium, 1/3 apical) is given in the supplementary data (S1). 
The FTIR spectra are shown in Fig. 3. The plots were prepared after cluster analysis of all spectra from specimens prepared with the different silanes and solvents. All clusters showed a similar pattern in the $1700-1200 \mathrm{~cm}^{-1}$ range. Two peaks at $2952 \mathrm{~cm}^{-1}$ and $2923 \mathrm{~cm}^{-1}$ correspond to symmetric stretching of the $\mathrm{C}-\mathrm{H}$ bond $\left(v_{1} \mathrm{C}-\mathrm{H}\right)$ and asymmetric stretching of the $\mathrm{C}-\mathrm{H}$ bond $\left(v_{3} \mathrm{C}-\mathrm{H}\right)$, respectively, from the silane aliphatic carbon chain. ${ }^{26,27}$ They appeared after OTS silanization with either DCM, acetone or ethyl acetate, while no peak appeared in this area after silanization with OTES (in ethanol). The strongest peaks were obtained for OTS silanization with ethyl acetate as solvent.

Water contact angle results are shown in Fig. 4. Before silanization, pretreatment induced a decrease of water contact angle from $68^{\circ} \pm 4$ for raw dentine to $51^{\circ} \pm 4(p=0.03)$ for pretreated dentine. Silanization with OTS/DCM and OTS/ethyl acetate induced a significant increase of water contact angle; these results were enhanced by pretreatment. Water contact angle of OTS/DCM silanized dentine increased to $115^{\circ} \pm 3$ for pretreated dentine and to $101^{\circ} \pm 4$ for raw dentine $(\mathrm{p}<0.01)$ (Fig. 4A). Different silanes and solvents were tested. Silanization with OTS was much more efficient than silanization with OTES: specimens remained hydrophilic after OTES silanization, but became hydrophobic after OTS silanization $\left(115^{\circ} \pm 3\right.$ after $\mathrm{OTS} / \mathrm{DCM}$ silanization and $70^{\circ} \pm 3$ after OTES silanization, $\mathrm{p}<0.05)$. Additionally, there was no significant difference between non-silanized, pretreated dentine $\left(51^{\circ} \pm 4\right)$ and OTES-silanized dentine $\left(70^{\circ} \pm 3, \mathrm{p}=0.1\right)$. Thus, OTES treatment was not selected for further evaluation. Pretreated dentine silanized with OTS in DCM solvent (OTS/DCM) was significantly more hydrophobic $\left(115^{\circ} \pm 3\right)$ than pretreated dentine silanized with OTS in ethyl acetate $\left(109^{\circ} \pm 4\right)$ or with OTS in acetone $\left(107^{\circ} \pm 4\right)$. There was no significant difference between pretreated dentine silanized with OTS/ethyl acetate or with OTS/acetone $(\mathrm{p}=0.5)$. There was a statistically significant difference between silanization with OTS in ethyl acetate or in acetone and silanization with OTES ( $<<0.05)$ (Fig. 4). 
Gas permeability test results are shown in Fig 5. The mean gas flow after 15 min was $1.62 \pm 0.2 \times 10^{-8} \mathrm{~mol} . \mathrm{s}^{-1}$ for silanized canals and $2.02 \pm 0.2 \times 10^{-8} \mathrm{~mol} . \mathrm{s}^{-1}$ for non-silanized canals, with a significant difference between the two groups $(\mathrm{p}=0.027)$. The measurements were performed in the Knudsen regime (15 $\mathrm{min}$ to $45 \mathrm{~min}$ after gas injection) without interaction between the gas molecules and the pore walls.

A similar effect of silanization on seal tightness was observed during the water permeability test (Fig 6). The mean water flow for silanized canals was $5.4 \pm 0.9 \times 10^{-3}$ $\mu$ L. min $^{-1}$ and $10.8 \pm 1.8 \times 10^{-3} \mu$ L.min ${ }^{-1}$ for non-silanized canals. A Student's t-test confirmed the statistical significance of the difference between flows $(p=0.04)$.

The silanized groups exhibited a better seal in both gas and water permeability tests, with statistically significant differences for both permeability tests.

\section{DISCUSSION}

A recent mathematical model of fluid penetration at the dentine-sealer interface sheds light on the importance of hydrophobic surfaces. ${ }^{7}$ Hydrophobicity should reduce water penetration by reversing capillary pressure. According to Jurin's law, capillary pressure depends on the surface water contact angle: $P c=\gamma\left(\cos \theta_{d}+\cos \theta_{s}\right) / d$ with $P c=$ capillary pressure, $\gamma=$ surface tension, $\theta_{d}=$ dentine contact angle, $\theta_{s}=$ sealer contact angle and $d=$ interstice width. An application of this mathematical model is given in the supporting information (S2).

The first goal of this study was to develop a pretreatment protocol to expose hydroxyl groups of collagen for grafting silane molecules onto carboxy-terminal domains. Our pretreatment protocol achieved disinfection targets, removing the smear layer and opening dentinal tubules to allow the antimicrobial activity of $\mathrm{NaOCl}$, as shown with SEM. The FTIR analysis showed that proteins were exposed. $\mathrm{NaOCl}$ induced a disappearance of the proteinrelated peaks (amide I and II), and the last EDTA rinse made these peaks reappear, showing a 
new exposure of collagen and consequently of hydroxyl groups. EDTA has a demineralization effect, while $\mathrm{NaOCl}$ degrades proteins. ${ }^{28,29} \mathrm{NaOCl}$ rinsing degrades exposed proteins, but proteins that are still embedded in the mineral matrix are protected. ${ }^{30}$ These proteins become exposed after a final EDTA rinse, when this protective mineral matrix is partially removed by demineralization. These results were confirmed by contact angle measurements showing a decreased contact angle after pretreatment. This pretreatment induced an even higher contact angle after silanization. By exposing organic polar groups, pretreatment increases hydrophilicity before silanization and allows better silanization with OTS. These results are consistent with previous studies on dentine wettability. ${ }^{31}$

After collagen exposure, the next goal was silanization: grafting long carbon chains onto the collagen. We tested several solvents, including ethanol, ethyl acetate and acetone, which are already used for clinical applications. ${ }^{32,33}$ Silanization with OTES was not effective in our study conditions ( 5 min heating), as shown by wettability and FTIR spectroscopic results; specimens stayed hydrophilic after silanization. Usually, the OTES reaction is accelerated by heating for 1 hour. ${ }^{34}$ Such a long heating time is not practical for in-mouth treatment. Therefore, we did not further investigate OTES silanization. Silanization with OTS in ethyl acetate or in acetone was as effective as silanization by OTS in DCM, with a clear hydrophobic effect confirmed by $\mathrm{C}-\mathrm{H}$ peaks appearing in FTIR spectroscopy. Along with these results, we considered the effects of each solvent on human beings. Dichloromethane (CAS 75-09-2) is harmful, with limited evidence of carcinogenic effect, and reasonably anticipated to be a human carcinogen. ${ }^{36,37}$ It is toxic if inhaled, if in contact with skin and if swallowed, with danger of very serious irreversible effects. ${ }^{38}$ Acetone is classified as an irritant, flammable and irritating to eyes. Ethyl acetate (CAS 141-78-6) is a colorless liquid with a characteristic sweet smell and is used in nail polish removers and cigarettes. The LD50 of ethyl acetate for rats is $11.3 \mathrm{~g} / \mathrm{kg}$, indicating low toxicity. ${ }^{39}$ 
Moreover, ethyl acetate is already used clinically. Ethyl acetate is used to dissolve endodontic pastes (DMS IV ${ }^{\circledR}$, Dentsply Maillfer, Ballaigues, Switzerland); its odor is well tolerated by patients. Taking into account the respective toxicity and hazards of acetone and ethyl acetate, we selected ethyl acetate as solvent because of its low toxicity and clinical use in endodontic treatment.

After successfully rendering the dentine surfaces hydrophobic, our next step was to test the influence of hydrophobicity on sealing tightness. We expected that the silanized specimens would show better adhesion because of hydrophobic interactions. Scanning electron microscopy examination revealed morphological differences: silanized dentine exhibited a smooth surface, with a layer covering dentinal tubules, whereas non-silanized dentine had wide-open tubules (Fig 1). ${ }^{35}$ The silanization reaction on dentine induces tubule closure and prevents micro-retentions caused by sealer penetration inside the tubules. These effects reduce the roughness of these surfaces. However, the main goal of endodontic sealing is not retention but tightness, especially for apical sealing. We therefore tested the effects of root canal dentine silanization on endodontic sealing tightness.

Gas permeability tests demonstrate unambiguously that silanized specimens have a better seal (Fig 5). Measurements of nitrogen flow give information about the porosity between the dentinal wall and sealer without the influence of surface wettability. The mean gas flow for the non-silanized root canal is double the flow of a $1 \mathrm{~cm}$ long capillary with a $15-\mu \mathrm{m}$ internal diameter $\left(1 \times 10^{-8} \mathrm{~mol}_{\mathrm{s}} \mathrm{s}^{-1}\right){ }^{19}$ This gives a good idea of the size of the network of pores existing at the interface between the dentine wall and cement.

For water permeability, the mean water flow is $5 \times 10^{-8}$ mole.s ${ }^{-1}-$ surprisingly close to the mean gas flow (Fig 6). The pores between the materials studied are equally permeable to gas and water. The gas permeability test shows a more significant difference between the two groups $(p=0.027)$, but this may be related to the number of specimens in each group (10 
for gas and 5 for water). These results may indicate that the effect of hydrophobic treatment on seal tightness is caused by the diminution of pores between the Dentine wall and sealer rather than by the prevention of water penetration with hydrophobic repulsive forces.

\section{CONCLUSION}

This study explored the influence of hydrophobic interactions on silicone-based sealer tightness after root canal dentine hydrophobic treatment. We developed a dentine pretreatment that exposed collagen fibers while meeting disinfection requirements. We adapted an already well-known silanization reaction with octadecylsilane to perform silanization on collagen hydroxyl under biocompatible and clinically usable conditions. We characterized the silanization process by measuring the hydrophobicity of the treated dentine surfaces. The hydrophobic treatment improves narrowness and tightness between the 2 hydrophobic interfaces, the silicone-based sealer and the hydrophobic dentine wall. Both permeability tests showed a better seal for silanized root canals compared with non-silanized root canals. Ideally, the root canal filling should be a barrier that prevents microbial leakage: the hydrophobization obtained by silanisation process prevents this leakage better than the micromechanical retention obtained by the non-silanization process. Further studies are needed to confirm the clinical relevance of the tightness improvement from the silanization reaction.

\section{Acknowledgements}

Partial funding for this study was provided through a project funded by the Institut National Polytechnique (Toulouse, France): "PCP Franco Mexicain" (Post-Graduate Cooperative Program France-Mexico).

John Wiley14 Sons, Inc. 


\section{Appendix A. Supplementary data}

Supplementary data associated with this article can be found in the online version.

\section{REFERENCES}

1. Whitworth JM, Baco L. Coronal leakage of sealer-only backfill: an in vitro evaluation. J Endod 2005;31(4):280-282.

2. Hülsmann M, Peters OA, Dummer. Mechanical preparation of root canals: shaping goals, techniques and means. Endodontic Topics 2005;10:30-76.

3. Oliver CM, Abbott PV. Correlation between clinical success and apical dye penetration. Int Endod J 2001;34:637-644.

4. Whitworth J. Methods of filling root canals: principles and practices. Endodontic Topics $2005 ; 12: 2-24$

5. Peters LB, Wesselink PR, Moorer WR. The fate and the role of bacteria left in root dentinal tubules. Int Endod J 1995;28:95-99.

6. Ørstavik D. Materials used for root canal obturation: technical, biological and clinical testing. Endodontic Topics 2005;12:25-38.

7. Romieu OJ, Zimányi L, Warszynski P, Levallois B, Cuisinier FJ, Deville de Périère D, Jacquot B. Modeling colorant leakage techniques: Application to endodontics. Dent Mater 2010;26:881-890.

8. Meyer EE, Rosenberg KJ, Israelachvili J. Recent progress in understanding hydrophobic interactions. Proc Natl Acad Sci USA 2006;103(43):15739-15746.

9. Hoefnagels HF, Wu D, de With G, Ming W. Biomimetic superhydrophobic and highly oleophobic cotton textiles. Langmuir 2007;23(26):13158-13153. 
10. Charola A. Salts in the deterioration of porous materials: an overview. J Am Inst Conserv 2000;39:327-343.

11. Kabanov AV, Batrakova EV. New technologies for drug delivery across the blood brain barrier. Curr Pharm Des 2004;10(12):1355-1363.

12. Bordenave N, Grenier S, Coma V. Hydrophobization and antimicrobial activity of chitosan and paper-based packaging material. Biomacromolecules 2010;11(1):88-96.

13. Angst DL, Simmons GW. Moisture Absorption Characteristics of Organosiloxane SelfAssembled Monolayers. Langmuir 1991;7:2236-2242.

14. Kulkarni SA, Mirji SA, Mandale AB, Vijayamohanan KP. Thermal stability of selfassembled octadecyltrichlorosilane monolayers on planar and curved silica surfaces. Thin Solid Films 2006;496:420-425.

15. Saleh K, Lazghab M, Guigon P. Chemical hydrophobisation of silica-based particles with n-Octadecyltrichlorosilane by solventless process in a fluidized-bed reactor. Powder Technology 2009;190:192-199.

16. Tsukagoshi T, Kondo Y, Yoshino N. Protein adsorption on polymer-modified silica particle surface. Colloids Surf B Biointerfaces 2007;54:101-107.

17. Kontakiotis EG, Tzanetakis GN, Loizides AL. A Comparative Study of Contact Angles of Four Different Root Canal Sealers. J Endod 2007;33(3):299-302.

18. Yu P. Applications of Hierarchical Cluster Analysis (CLA) and Principal Component Analysis (PCA) in Feed Structure and Feed Molecular Chemistry Research, Using Synchrotron-Based Fourier Transform Infrared (FTIR) Microspectroscopy. J Agric Food Chem 2005:53(18);7115-7127

19. Romieu OJ, Jacquot B, Callas-Etienne S, Collart Dutilleul PY, Levallois B, Cuisinier FJ. Gas permeability: a new quantitative method to assess endodontic leakage. Biomed Tech 2008;53(4):181-184.

John Wiley ${ }^{16}$ Sons, Inc. 
20. Marcus Y. The Properties of Solvents, vol. 4, England: John Wiley \& Sons Ltd ; 1999. p 239.

21. Beurroies I, Bourret D, Sempere R, Duffours L, Phalippou J. Gas permeability of partially densified aerogels. J Non-Cryst Solids 1995;186:328-333.

22. Cobankara FK, Adanir N, Belli S. Evaluation of the influence of smear layer on the apical and coronal sealing ability of two sealers. J Endod 2004;30(6):406-409.

23. Shemesh H, Van Den Bos M, Wu MK, Wesselink PR. Glucose penetration and fluid transport through coronal root structure and filled root canals. Int Endod J 2007;40:866872.

24. Jung C. Insight into protein structure and protein-ligand recognition by Fourier transform infrared spectroscopy. J Mol Recognit 2000;13:325-351.

25. Magne D, Guicheux J, Weiss P, Pilet P, Daculsi G. Fourier Transform Infrared Microspectroscopic Investigation of the Organic and Mineral Constituents of Peritubular Dentin: A Horse Study. Calcif Tissue Int 2002;71:179-185.

26. Li YS, Wang Y, Ceesay S. Vibrational spectra of phenyltriethoxysilane, phenyltrimethoxysilane and their sol-gels. Spectrochim Acta A Mol Biomol Spectrosc $2009 ; 71: 1819-1824$.

27. Mirji SA, Halligudi SB, Sawant DP, Jacob NE, Patil KR, Gaikwad AB, Pradhan SD. Adsorption of octadecyltrichlorosilane on mesoporous SBA-15. Appl Surf Sci 2006;252:4097-4103.

28. Strawn SE, White JM, Marshall GW, Gee L, Goodis HE, Marshall SJ. Spectroscopic changes in human dentine exposed to various storage solutions-short term. J Dent 1996;24(6):417-423.

John Wiley ${ }^{17}$ Sons, Inc. 
29. Verdelis K, Eliades G, Oviir T, Margelos J. Effect of chelating agents on the molecular composition and extent of decalcification at cervical, middle and apical root dentin locations. Endod Dent Traumatol 1999;15(4):164-170.

30. Zhang K, Kyung Kim Y, Cadenaro M, Bryan TE, Sidow SJ, Loushine RJ, Ling JQ, Pashley DH, Tay FR. Effects of Different Exposure Times and Concentrations of Sodium Hypochlorite/Ethylenediaminetetraacetic Acid on the Structural Integrity of Mineralized Dentin. J Endod 2010;36(1):105-109.

31. Hitmi L, Bouter D, Degrange M. Influence of drying and HEMA treatment on dentin wettability. Dent Mater 2002;18:503-511.

32. Demiryürek EO, Külünk S, Saraç D, Yüksel G, Bulucu B. Effect of different surface treatments on the push-out bond strength of fiber post to root canal dentin. Oral Surg Oral Med Oral Pathol Oral Radiol Endod 2009;108(2):74-80.

33. Gentil M, Pereira JV, Sousa YT, Pietro R, Neto MD, Vansan LP, de Castro França S. In vitro evaluation of the antibacterial activity of Arctium lappa as a phytotherapeutic agent used in intracanal dressings. Phytother Res 2006;20(3):184-186.

34. Bluemel J. Reactions of Ethoxysilanes with Silica: A Solid-State NMR Study. J Am Chem Soc 1995;117(7):2112-2113.

35. Kim YK, Grandini S, Ames JM, Gu LS, Kim SK, Pashley DH, Gutmann JL, Tay FR. Critical review on methacrylate resin-based root canal sealers. J Endod 2010;36(3):383399.

36. Bale AS, Barone S, Scott CS, Cooper GS. A review of potential neurotoxic mechanisms among three chlorinated organic solvents. Toxicol Appl Pharmacol 2011;255(1):113-126.

37. Official Citation: NTP. 2011. Report on Carcinogens, Twelfth Edition. Research Triangle Park, NC: U.S. Department of Health and Human Services, Public Health Service, National Toxicology Program. pp 148-150.

John Wiley ${ }^{18}$ Sons, Inc. 
38. Toxicological Profile for Methylene Chloride, U.S. Department of Health and Human Services, Public Health Service, Agency for Toxic Substances and Disease Registry, September 2000. URL www.atsdr.cdc.gov/toxprofiles/tp14.pdf available October 2011.

39. Riemenschneider W, Bolt HM. Esters, Organic. Ullmann's Encyclopedia of Industrial Chemistry, Wiley-VCH, Weinheim, 2005. DOI: 10.1002/14356007.a09_565.pub2

John Wiley 19 Sons, Inc. 


\section{Figure legends}

Figure 1: Effects of pretreatment and silanization on dentine (SEM)

A, B: Raw dentin with tubule opening partially covered by smear layer.

C, D: After 3 minutes in a 17\% EDTA solution, the smear layer disappears and tubule openings are irregular.

E, F: After 3 minutes in a 17\% EDTA solution and 5 minutes in a $2.5 \% \mathrm{NaOCl}$ solution, clean tubule openings with regular margins are observed.

G, H: After 3 minutes in a 17\% EDTA solution, 5 minutes in a $2.5 \% \mathrm{NaOCl}$ solution and 3

minutes in a $17 \%$ EDTA solution, wide tubule openings with soft margins caused by

demineralization are observed.

I, J: Pretreated dentine after silanization using OTS and acetone as solvent.

Figure 2: Cluster analysis of FTIR spectra of dentine during pretreatment.

Hierarchical clustering of all the spectra of root dentine based on the spectral range of 1700$1200 \mathrm{~cm}^{-1}$ representing typical dentine structure for the pretreatment procedure.

Figure 3: FTIR analysis of silanization.

Cluster means determined after hierarchical cluster analysis of all the spectra focusing on the spectral range $3000-2700 \mathrm{~cm}^{-1}$. Each cluster groups all the spectra from one silanization treatment. Two peaks at 2952 and $2923 \mathrm{~cm}^{-1}$ correspond, respectively, to symmetric stretching of the $\mathrm{C}-\mathrm{H}$ bond $\left(v_{1} \mathrm{C}-\mathrm{H}\right)$ and asymmetric stretching of the $\mathrm{C}-\mathrm{H}$ bond $\left(v_{3} \mathrm{C}-\mathrm{H}\right)$ from the silane aliphatic carbon chains. Peaks are absent when using OTES in ethanol. The strongest peaks are obtained for OTS silanization with ethyl acetate as solvent.

Figure 4: Water Contact Angle before and after pretreatment and silanization.

Raw dentine vs. pretreatment: $\mathrm{p}=0.03$

OTS/DCM silanized raw dentine vs. OTS/DCM silanized pretreated dentine: $p<0.01$

OTS/ethyl acetate silanized raw dentine vs. OTS/ ethyl acetate silanized pretreated dentine: $\mathrm{p}<0.01$

Pretreated Dentine vs. OTES/ethanol silanized pretreated Dentine, $\mathrm{p}=0.1$, N.S.

OTS/DCM silanized pretreated dentine vs. OTS/ethyl acetate silanized pretreated dentine: $\mathrm{p}=0.01$

OTS/DCM silanized pretreated dentine vs. OTS/acetone silanized pretreated dentine: $\mathrm{p}<0.01$

OTS/acetone silanized pretreated dentine vs. OTS/ethyl acetate silanized pretreated dentine, $\mathrm{p}=0.5$, N.S

Figure 5: Gas permeability

Gas flow through silanized and non-silanized specimens. The flow results from the gas pressure difference between the two chambers separated by the sealed specimens. More leakage occurs with non-silanized specimens.

Figure 6: Water permeability

Water flow through sealed root canals was measured after flow stabilization.

Leakage through non-silanized specimens is significantly higher than through silanized specimens. 

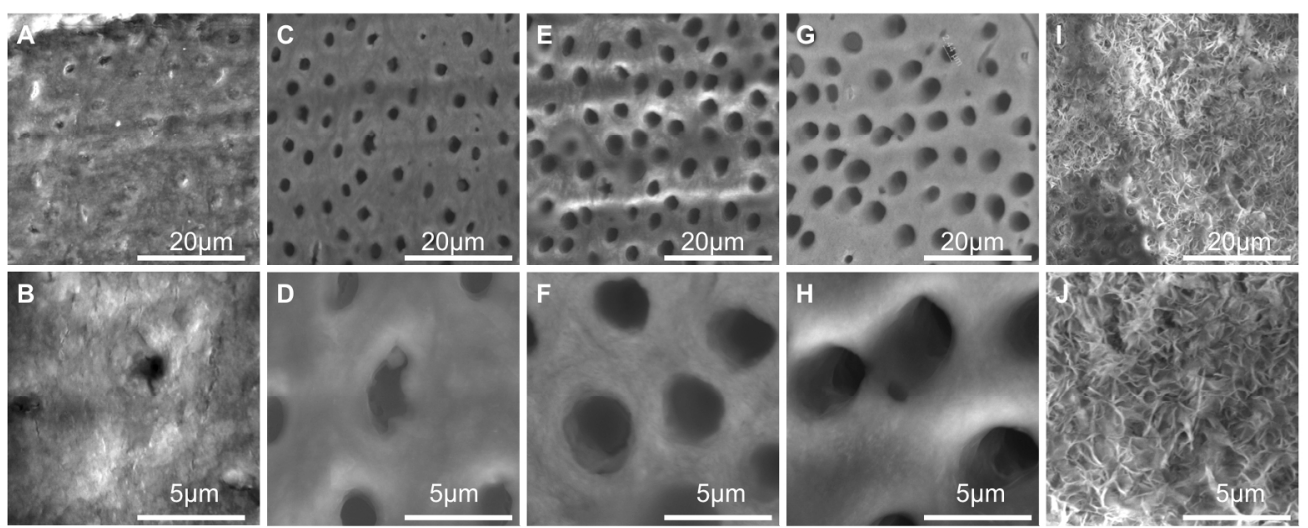

Effects of pretreatment and silanization on dentine (SEM)

A, B: Raw dentin with tubule opening partially covered by smear layer.

C, D: After 3 minutes in a 17\% EDTA solution, the smear layer disappears and tubule openings are irregular.

$\mathrm{E}, \mathrm{F}$ : After 3 minutes in a $17 \%$ EDTA solution and 5 minutes in a $2.5 \% \mathrm{NaOCl}$ solution, clean tubule openings with regular margins are observed.

G, H: After 3 minutes in a $17 \%$ EDTA solution, 5 minutes in a $2.5 \% \mathrm{NaOCl}$ solution and 3 minutes in a $17 \%$ EDTA solution, wide tubule openings with soft margins caused by demineralization are observed.

I, J: Pretreated dentine after silanization using OTS and acetone as solvent $361 \times 144 \mathrm{~mm}(150 \times 150 \mathrm{DPI})$ 


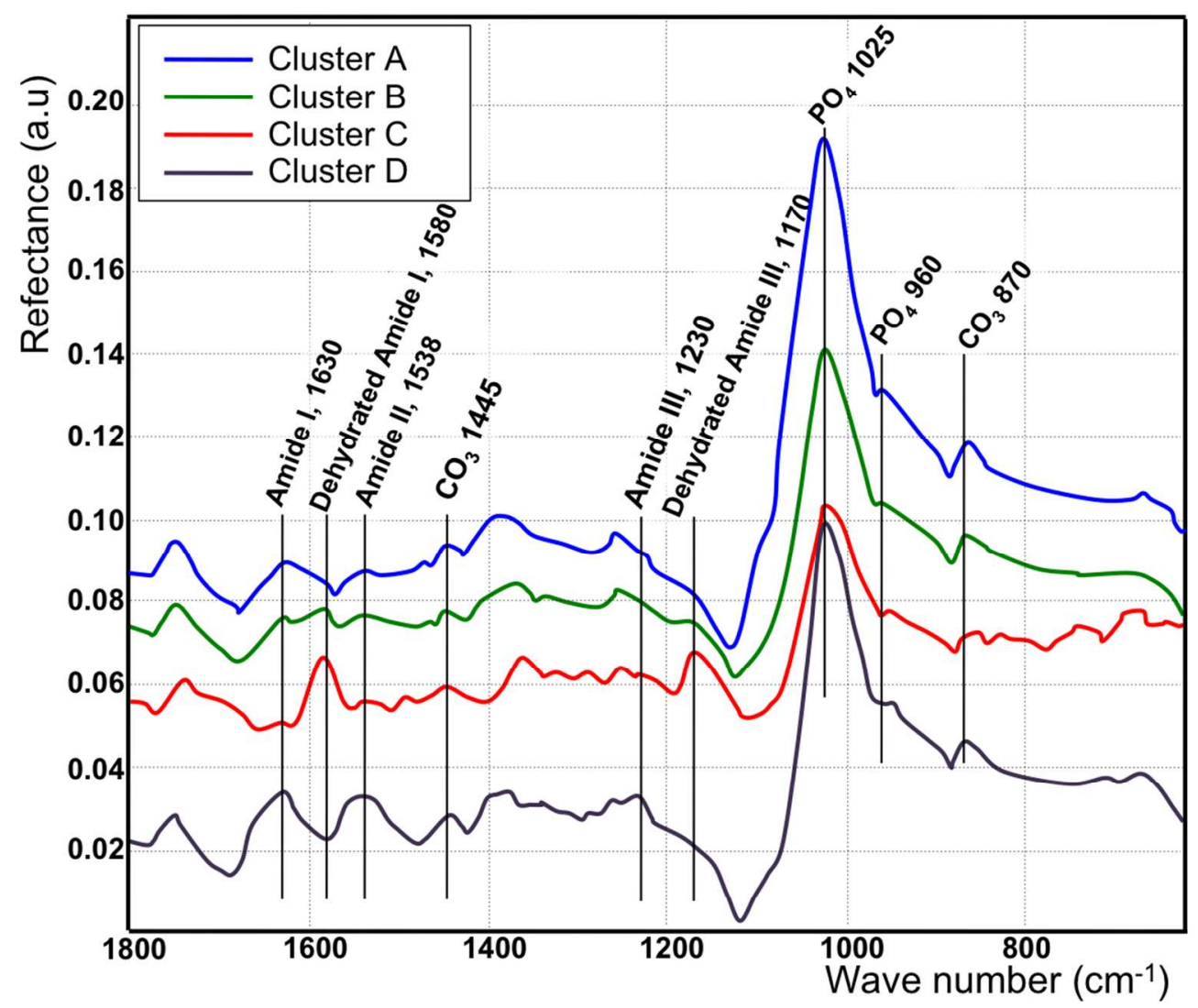

Cluster analysis of FTIR spectra of dentine during pretreatment.

Hierarchical clustering of all the spectra of root dentine based on the spectral range of $1700-1200 \mathrm{~cm}-1$ representing typical dentine structure for the pretreatment procedure $199 \times 172 \mathrm{~mm}(150 \times 150 \mathrm{DPI})$ 


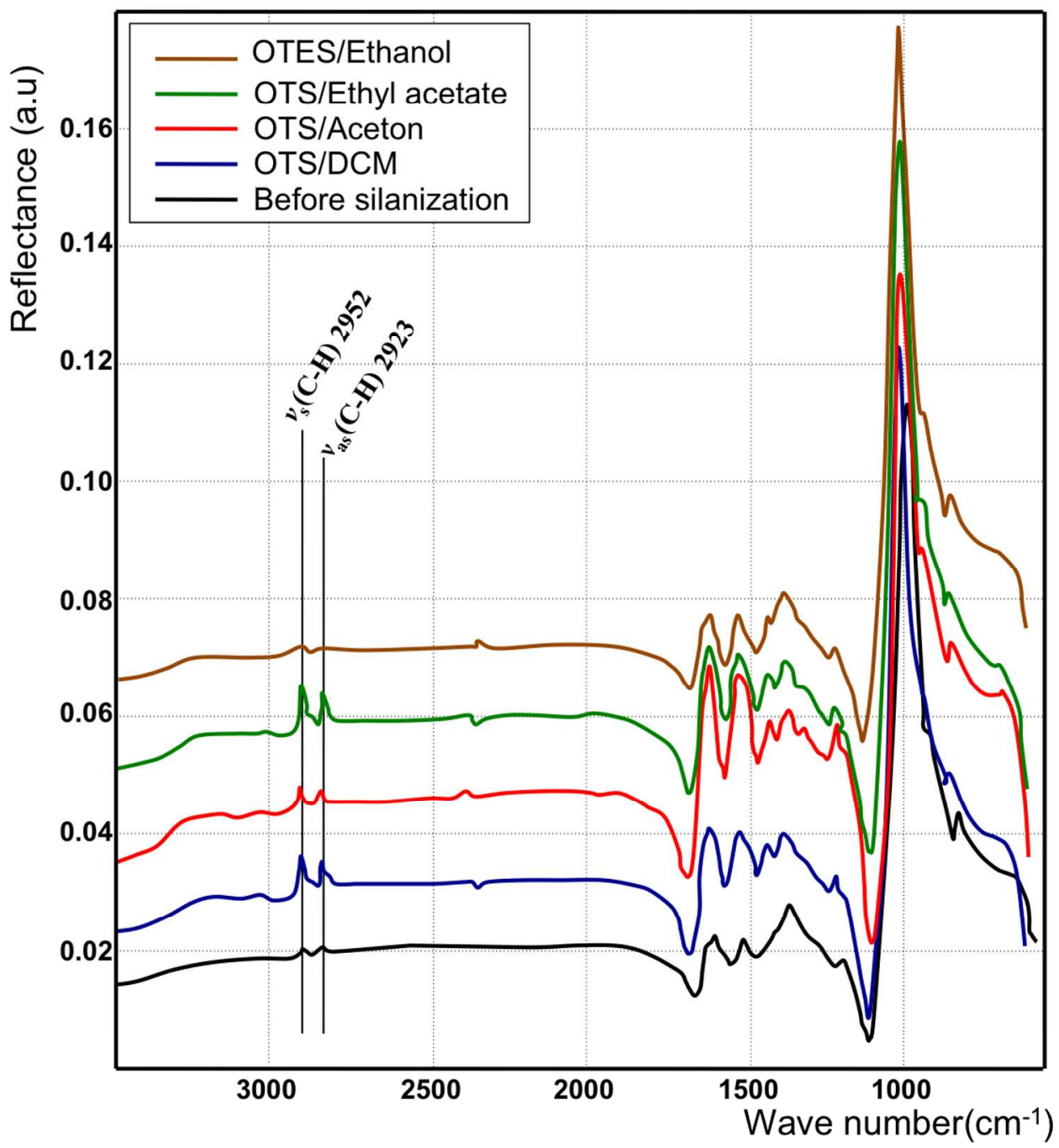

FTIR analysis of silanization.

Cluster means determined after hierarchical cluster analysis of all the spectra focusing on the spectral range $3000-2700 \mathrm{~cm}-1$. Each cluster groups all the spectra from one silanization treatment. Two peaks at 2952 and $2923 \mathrm{~cm}-1$ correspond, respectively, to symmetric stretching of the $\mathrm{C}-\mathrm{H}$ bond $(\mathrm{v} 1 \mathrm{C}-\mathrm{H})$ and asymmetric stretching of the $\mathrm{C}-\mathrm{H}$ bond $(\mathrm{v} 3 \mathrm{C}-\mathrm{H})$ from the silane aliphatic carbon chains. Peaks are absent when using OTES in ethanol. The strongest peaks are obtained for OTS silanization with ethyl acetate as solvent $197 \times 209 \mathrm{~mm}(150 \times 150 \mathrm{DPI})$ 


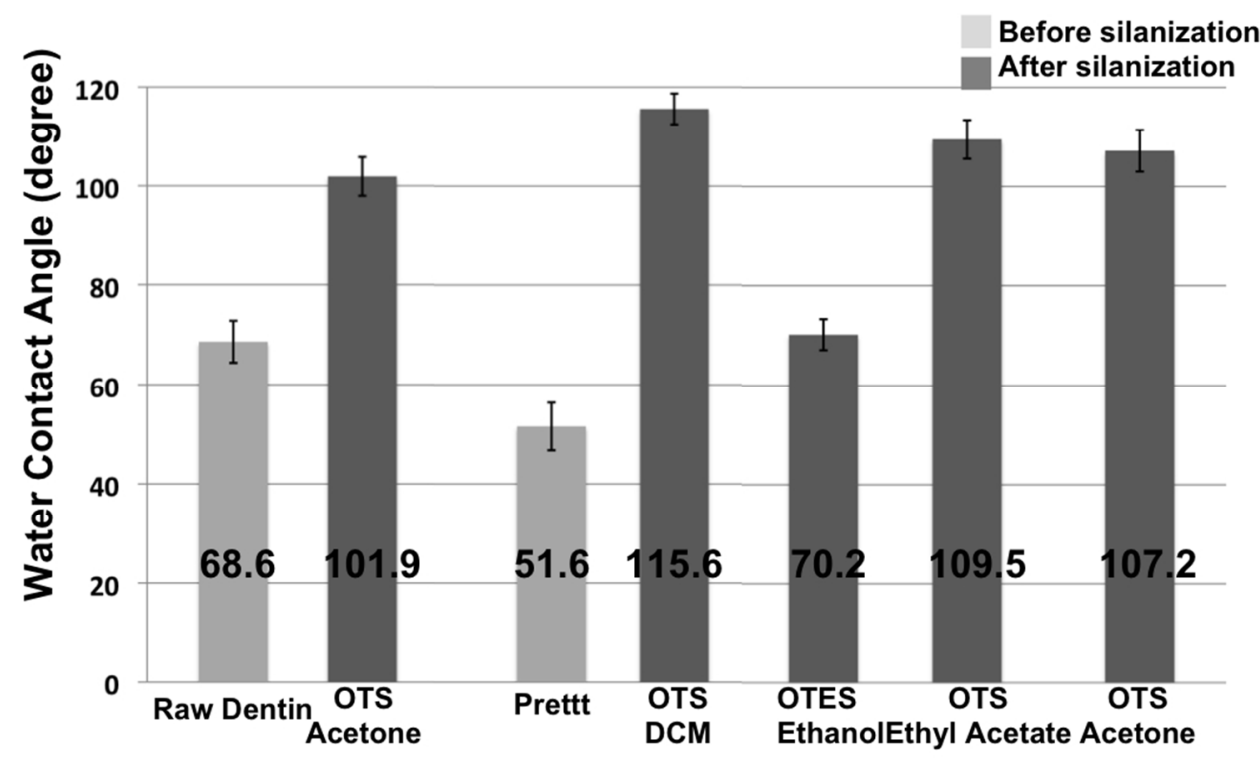

Water Contact Angle before and after pretreatment and silanization $186 \times 110 \mathrm{~mm}(150 \times 150 \mathrm{DPI})$ 


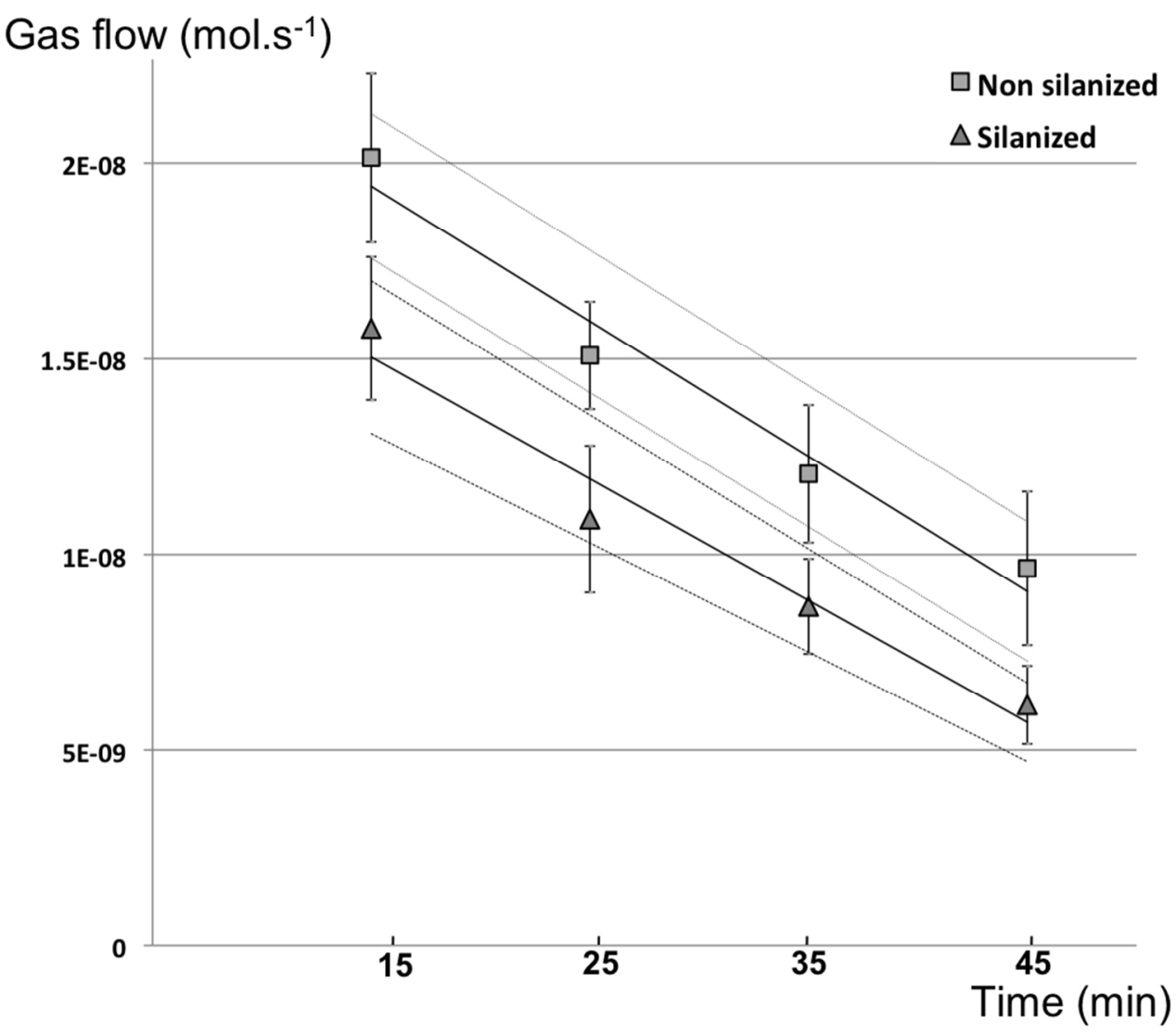

Gas permeability

Gas flow through silanized and non-silanized samples. The flow results from the gas pressure difference between the two chambers separated by the sealed samples. More leakage occurs with non-silanized samples

$182 \times 156 \mathrm{~mm}(150 \times 150 \mathrm{DPI})$

John Wiley \& Sons, Inc. 


\section{Liquid Flow $\left(\mu\right.$ L. $\left.\min ^{-1}\right)$}

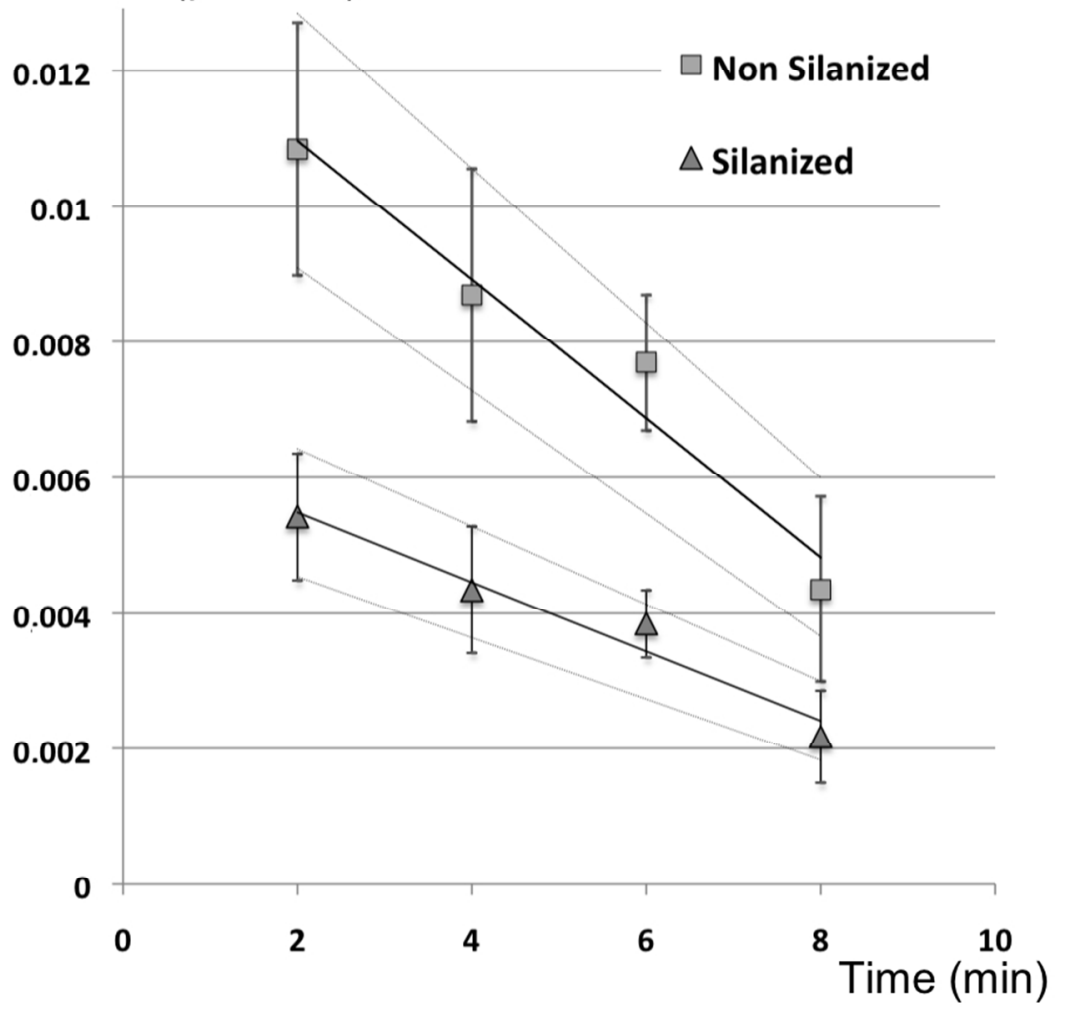

Water permeability

Water flow through sealed root canals was measured after flow stabilization. Leakage through non-silanized samples is significantly higher than through silanized samples $187 \times 155 \mathrm{~mm}(150 \times 150 \mathrm{DPI})$

John Wiley \& Sons, Inc. 


\begin{tabular}{|l|l|l|l|}
\hline & Coronal & Medium & Apical \\
\hline Raw Dentine & A & C & B \\
\hline EDTA1 & B & A & A \\
\hline NaOCl & A & A & D \\
\hline EDTA2 & D & D & \\
\hline
\end{tabular}

Table 1. Cluster repartition for different dentine treatments in three root areas (1/3 coronal, $1 / 3$ medium, 1/3 apical):

Raw dentin with tubule opening partially covered by smear layer EDTA1: after 3 minutes in a 17\% EDTA solution $\mathrm{NaOCl} \mathrm{E}$ : after 3 minutes in a 17\% EDTA solution and 5 minutes in a $2.5 \% \mathrm{NaOCl}$ solution EDTA2: after 3 minutes in a 17\% EDTA solution, 5 minutes in a $2.5 \% \mathrm{NaOCl}$ solution and 3 minutes in a 17\% EDTA solution 